\title{
Premature ejaculation: is there an efficient therapy?
}

\author{
Ejaculação precoce: existe terapia eficiente?
}

\author{
Fábio Barros de Francischi ${ }^{1}$, Daniel Cernach Ayres $^{1}$, Ricardo Eidi Itao ${ }^{1}$, Luis Cesar Fava Spessoto ${ }^{1}$, Jose Germano \\ Ferraz de Arruda ${ }^{1}$, Fernando Nestor Facio Junior ${ }^{1}$
}

\begin{abstract}
Premature ejaculation is the most frequent male sexual dysfunction, estimated to affect 20 to $30 \%$ of men at some time in their life. A Pubmed search from the year 2000 to the present was performed to retrieve publications related to management or treatment of premature ejaculation. Behavioral techniques have been the mainstay of premature ejaculation management for many years, although evidence of their short-term efficacy is limited. Topical therapies for premature ejaculation act by desensitizing the penis and do not alter the sensation of ejaculation. Selective serotonin reuptake inhibitors (SSRIs), commonly used in the treatment of depression, are often used to treat premature ejaculation, based on the observation that delayed ejaculation is a frequent side effect of this drug class. Dapoxetine is a short-acting SSRI formulated to treat premature ejaculation, and results seem very promising.
\end{abstract}

Keywords: Ejaculation; Coitus; Erectile dysfunction; Sexual behavior; Sex education; Serotonin reuptake inhibitors

\section{RESUMO}

A ejaculação precoce é a disfunção sexual masculina mais frequente, com uma estimativa de acometimento de 20 a $30 \%$ dos homens em algum momento da vida. Foi realizada uma busca no Pubmed, do ano 2000 até os dias atuais, com a finalidade de revisar publicações relacionadas ao manejo e ao tratamento da ejaculação precoce. Terapias comportamentais foram a base do manejo da ejaculação precoce por muitos anos, embora as evidências de sua eficácia a curto prazo sejam limitadas. Terapias de uso tópico agem por meio de dessensibilização do pênis, mas não alteram a sensação da ejaculação. Os inibidores seletivos da recaptação da serotonina são utilizados para depressão e, em geral, também para tratar ejaculação precoce, com base na observação de que o retardo na ejaculação é um efeito colateral frequente dessa classe de drogas. A dapoxetina é um inibidor seletivo da recaptação da serotonina de curta ação, que foi formulado para tratar a ejaculação precoce, e seus resultados parecem muito promissores.

Descritores: Ejaculação; Coito; Disfunção erétil; Comportamento sexual; Educação sexual; Inibidores de captação de serotonina

\section{INTRODUCTION}

Premature ejaculation $(\mathrm{PE})$ is the most frequent male sexual dysfunction with an estimated 20 to $30 \%$ of men at some time in their life $\mathrm{f}^{(1)}$. Historically, attempts to explain the etiology of PE included a diverse range of biological and psychological theories. Most of these proposed etiologies are not based on evidence and are speculative at best. Psychological theories include the effect of early experience and sexual conditioning, anxiety, sexual technique, the frequency of sexual activity, and psychodynamic explanations. Biological explanations include evolutionary theories, penile hypersensitivity, central neurotransmitter levels and receptor sensitivity, degree of arousability, speed of ejaculatory reflex, and level of sex hormones. There is little empirical evidence to suggest a causal nexus between PE and any of the factors thought to cause $\mathrm{PE}^{(2)}$.

\section{METHODS}

A Pubmed search from the year 2000 to the present was performed to retrieve publications related to management or treatment of $\mathrm{PE}$, or male sexual dysfunction. The publications were included if they reported the impact of $\mathrm{PE}$ on man, his partner or the relationship, or the impact of male sexual dysfunction and included PE in the analysis. Older references were used in case of relevance.

\section{Premature ejaculation concept}

The DSM-IV TR defines PE as "persistent or recurrent onset of orgasm and ejaculation with minimal sexual stimulation before, on, or shortly after penetration and before the person wishes it", which "cause(s) marked distress or interpersonal difficulty"(3).

Hospital de Base da Faculdade de Medicina de São José do Rio Preto - FAMERP, São José do Rio Preto (SP), Brazil.

Corresponding author: Fernando Nestor Facio Junior - Avenida Fernando Correia Pires, 3.600 - Redentora - CEP 15015-040 - São José do Rio Preto (SP), Brazil - Tel.: (17) 3232-0199 - E-mail:

fnfacio@yahoo.com.br

Received on: Nov 27, 2010 - Accepted on: Nov 3, 2011 
Waldinger et al. ${ }^{(4)}$ advocated the use of activityspecific terms for ejaculation latency time (ELT) (such as intravaginal ejaculation latency time or IELT, in the intravaginal case; OELT in the case of oral sex, and so forth) rather than a more global term such as "penetration ejaculation latency time", which would include any sexual activity except masturbation and manual stimulation by partner. Different sexual activities may thus have significantly different physical and tactile characteristics, which may in turn be differently associated with the ejaculatory reflex.

\section{Diagnosis}

When making a diagnosis, physicians should also consider the frequency of PE episodes and the time over which PE has been a problem ${ }^{(5)}$. This information will help determine whether PE is generalized or situational and whether it is lifelong ('primary PE', since inception of sexual activity) or acquired ('secondary PE', developed after a period of time without PE). Men with PE, whether lifelong or acquired, generally report low or no sense of control over ejaculation, as well as low satisfaction with sexual intercourse, and increased interpersonal distress/bother compared with men without $\mathrm{PE}$, in addition to shorter average latency time in the majority of sexual intercourse episodes $^{(6)}$. This suggests that a complete diagnosis for PE should incorporate measures of control, latency time, distress and/or bother resulting from PE and sexual satisfaction.

\section{Age and erectile dysfunction in premature ejaculation}

Age has traditionally been considered as a causal factor of PE with younger men having presumably more problems with $\mathrm{PE}^{(7)}$, but more recent research has suggested that this effect of age was vastly exaggerated, or that age may even be negatively associated with PE. Age and/or relationship length may be associated with the frequency and type of sexual activities a person engages in, and these may in turn influence $\mathrm{ELT}^{(8)}$.

Recent data demonstrate that almost half of men with erectile dysfunction (ED) also experience $\mathrm{PE}^{(9)}$. Men with early ED may intentionally "rush" sexual intercourse to prevent premature loss of their erection and ejaculate with a brief latency. This may be compounded by the presence of high levels of performance anxiety related to their ED which serves only to worsen their prematurity. In the absence of a thorough sexual history, these men may be incorrectly diagnosed as suffering from PE and not from the underlying $\mathrm{ED}^{(9)}$.

\section{Pathophysiology}

There is, however, limited correlation evidence to suggest that lifelong PE is due to altered sensitivity of central 5-HT (serotonin) receptors and acquired PE is due to high levels of sexual anxiety, ED or lower urinary tract infection ${ }^{(2)}$. Ejaculatory latency time is probably a biological variable, which is genetically determined and may differ between populations and cultures, ranging from "extremely rapid" to "average to slow" ejaculation ${ }^{(2)}$. Hyposensitivity of the 5-HT2C and/or hypersensitivity of the 5-HT1A receptors were suggested as a possible explanation of lifelong $\mathrm{PE}^{(2)}$. Men with low 5-HT neurotransmission and probable 5-HT2C receptor hyposensitivity may have their ejaculatory threshold genetically "set" at a lower point and ejaculate quickly and with minimal stimulation, whereas men with a higher set-point can sustain more prolonged and higher levels of sexual stimulation and can exert more control over ejaculation ${ }^{(2)}$. Men with a very high set-point may experience delayed or absent ejaculation despite achieving a full erection and prolonged sexual stimulation ${ }^{(2)}$.

There is strong evidence that long duration of physical effort in men leads to a decrease in extracellular magnesium concentration due to a transient shift between extracellular and intracellular magnesium components and a simultaneous increase in urinary excretion $^{(10)}$. This transient hypomagnesaemia may be manifested by uncontrolled contractility of the male genital tract, causing emission and ejaculation ${ }^{(10)}$.

\section{TREATMENTS OPTIONS}

\section{Behavioral and cognitive therapy}

Behavioral techniques have been the mainstay of PE management for many years, although evidence of their short-term efficacy is limited. Some men use self-help approaches gained through personal experience, bibliotherapy (books), or online research. These techniques include masturbation just prior to intercourse, the use of multiple condoms to reduce penile sensitivity, or engaging in distraction techniques (mental exercises) during foreplay, intercourse, or both.

Anxiety was reported as a cause of PE by multiple authors and is entrenched in the folklore of sexual medicine as the most likely cause of PE despite scant empirical research evidence to support any causal role ${ }^{(11)}$. Several authors suggested that anxiety activates the sympathetic nervous system and reduces the ejaculatory threshold as a result of an earlier emission phase of ejaculation ${ }^{(11)}$.

The causal nexus between anxiety and PE is speculative, is not supported by any empirical evidence 
and is, in fact, contrary to empirical evidence from some researchers ${ }^{(12)}$.

Behavioral approaches generally focused on the physical aspect of PE, including the "squeeze" technique, as first described by Masters and Johnson, in $1970^{(13)}$ and the "stop-start" method, described by Semans, in $1956^{(14)}$. These involve engaging in sexual foreplay until just before the point of ejaculation and then either squeezing the head of the penis or stopping sexual activity until the urge to ejaculate subsides, at which point sexual activity may be resumed and the techniques repeated as necessary.

However, subsequent trials reported high failure rates with these techniques ${ }^{(15)}$.

Cognitive or sex therapy focuses on perceptions and feelings, improving communication between partners, increasing sexual skills and self-confidence, and reducing anxiety associated with sexual activity ${ }^{(16)}$. Short-term improvement with these behavioral approaches was observed; however, there are limited data concerning the efficacy of these methods in the long run ${ }^{(17)}$.

More recently, sex therapists combined psychotherapy with behavioral exercises with more success. Therapy focuses on the emotional implications of PE, in relationship dynamics, and in performance anxiety management. Therapy is limited by cost, local availability of trained therapists, and willingness of patients and partners to participate. As might be expected, the best results were seen in men who were motivated, were hopeful, and were in a stable monogamous relationship with a cooperative partner ${ }^{(18)}$.

\section{Topical therapies}

Topical therapies for PE act by desensitizing the penis and do not alter the sensation of ejaculation ${ }^{(19)}$. A topical cream containing local anesthetics lidocaine and prilocaine was effective in prolonging mean IELT by 6 to 8 minutes (versus 1 to 2 minutes with placebo; $\mathrm{p}<0.05$ ), but this must be applied at least 20 minutes (no longer than 45 minutes) prior to sexual contact ${ }^{(20)}$.

Korean researchers have developed a topical cream (SS-cream) from natural products, which has local anesthetic properties and is applied on the penis 1 hour before sexual contact ${ }^{(19)}$. In two randomized, doubleblind clinical trials, SS-cream (a 20-g dose) achieved a mean IELT of approximately 11 minutes, compared with 2.5 minutes for placebo ${ }^{(21)}$.

\section{Drug therapy}

Selective serotonin reuptake inhibitors (SSRIs) are commonly used in treatment of depression and often used to treat PE, based on the observation that delayed ejaculation is a frequent side effect of this drug class. Treatment with an SSRI class drug activates 5-HT2C receptor, elevates the ejaculatory threshold set-point and delays ejaculation ${ }^{(11)}$. The extent of ejaculatory delay may vary widely in different men according to the dosage and frequency of administration of SSRI and the genetically determined ejaculatory threshold set-point ${ }^{(11)}$. Cessation of treatment results in reestablishment of the previous set-point within 5 to 7 days in men with lifelong $\mathrm{PE}^{(11)}$.

Results of several studies showed that long-acting SSRIs significantly prolonged IELT in men with PE when administered as a daily dose for a long period.

A key limitation of therapy for PE with currently available SSRIs is that in addition to delaying ejaculation, this class of drugs has been associated with a number of unwanted sexual side effects. Decreased libido (41 to $64 \%$, in men and women), anorgasmia (31 to 53\%, in men and women), and impotence/ED (10 to 41\%) were observed following treatment with fluoxetine, paroxetine, fluvoxamine, sertraline, and citalopram ${ }^{(22)}$.

Other systemic treatments that were evaluated for management of PE include phosphodiesterase-5 (PDE-5) inhibitors, currently licensed to treat ED. The potential mechanism of action of PDE-5 inhibitors in the treatment of PE is unclear ${ }^{(23)}$. Despite the success of PDE-5 inhibitors in treating ED, there are limited data to suggest that these agents are effective in men with no ED. The combination of an SSRI and PDE-5 inhibitors may improve IELT significantly more than the SSRI alone, but the incidence of side effects is increased as compared to monotherapy with either of these agents ${ }^{(24)}$. Treatment with PDE-5 inhibitors may be effective in men with associated ED and PE, and these two conditions commonly occur together(25).

Dapoxetine is a novel short-acting SSRI under development for treatment of PE. In preclinical models, the drug was shown to significantly inhibit ejaculatory expulsion reflexes, acting at supraspinal level( ${ }^{(26)}$. Similar to other SSRIs, dapoxetine exerts its effects primarily through inhibition of serotonin reuptake transporter, with minimal inhibitory activity at the norepinephrine and dopamine reuptake transporters ${ }^{(27)}$. However, unlike long-acting SSRIs, which are typically administered in a chronic (daily) fashion and may take days or weeks to reach steady-state plasma concentrations ${ }^{(28)}$, dapoxetine is a short-acting SSRI, which may be better suited to treat $\mathrm{PE}^{(29)}$.

In the integrated analysis of two clinical trials ${ }^{(30)}$, the proportion of partners whose satisfaction with sexual intercourse at baseline was "fair," "good," or "very good" ranged from 53 to $58 \%$ across the treatment groups. At the end of this study, this proportion remained unchanged in the placebo arm, whereas in the dapoxetine 
30 and $60 \mathrm{mg}$ groups, the proportion increased to 72 and $78 \%$, respectively ( $p<0.0001$ for both). In several studies dapoxetine was shown to significantly improve the intravaginal ejaculatory latency time as compared with baseline and placebo, that is, 1.66 minutes, 3.03 minutes and 3.15 minutes, for placebo, dapoxetine 30 $\mathrm{mg}$ and $60 \mathrm{mg}$, respectively, when the drug was taken 30 to 60 minutes before intercourse. When taken 3 to 4 hours prior to intercourse, the IELT was 1.79 minutes, 3.06 minutes and 3.97 minutes, for placebo, $30 \mathrm{mg}$ and $60 \mathrm{mg}$ dapoxetine, respectively ${ }^{(30)}$. Similar improvements were observed for the female partner's perception of the man's control over ejaculation ${ }^{(31)}$.

\section{DISCUSSION}

$\mathrm{PE}$ is the most frequent male sexual dysfunction with an estimated 20 to $30 \%$ of men reporting PE (variously defined) at some time in their life ${ }^{(1)}$. Despite this prevalence rate, few men receive effective medical or psychological treatment for PE, although men reported self-treatment with a variety of behavioral approaches, creams, or herbal products ${ }^{(32)}$. Failure to seek treatment may be attributable to personal sensitivity about the problem, failure of men or their primary care physicians to discuss sexual issues, and perceptions that there are no effective interventions.

The Global Study of Sexual Attitudes and Behaviors revealed that only $9 \%$ of men reported being asked about their sexual health by a physician during a routine visit in the prior 3 years ${ }^{(33)}$. In contrast, $48 \%$ of the men believed that a physician should routinely ask about sexual health concerns ${ }^{(33)}$.

A team approach involving a psychotherapist and a physician may best help those couples who suffer more distress or who do not respond to initial therapy. The concept of coaching is within the reach of primary care providers who are sensitive and have time, interest and knowledge to offer the patient brief and targeted psychoeducational interventions. These basic sexual counseling sessions, together with drug therapy, should include efforts to gain feedback on efficacy of self-help and behavioral techniques in the context of the couple sexual relations. These efforts should focus on reducing performance anxiety and bolstering the patient's selfesteem and the couple's communication.

\section{CONCLUSION}

Premature ejaculation is a condition that affects men of all ages. It is the most frequent male sexual dysfunction and has significant effects on quality of life for both man and his partner. Several approaches have been used in its treatment, including cognitive and behavioral therapy, topical agents and drug therapy, such as PDE-5 inhibitors, as well as SSRIs. Dapoxetine is a short-acting SSRI that was formulated to treat PE and the results seem very promising.

\section{REFERENCES}

1. Montorsi F. Prevalence of premature ejaculation: a global and regional perspective. J Sex Med. 2005;2 (Suppl 2):96-102.

2. Waldinger MD. The neurobiological approach to premature ejaculation. J Urol. 2002;168(6):2359-67.

3. Diagnostic and statistical manual of mental disorders DSM-IV-TR. 4th ed. Washington: American Psychiatric Association; 2000.

4. Waldinger MD. Four measures of investigating ejaculatory performance. J Sex Med. 2007;4(2):520.

5. Rowland DL, Cooper SE, Schneider M. Defining premature ejaculation for experimental and clinical investigations. Arch Sex Behav. 2001;30(3):235-53.

6. Rosen RC, McMahon CG, Niederberger C, Broderick GA, Jamieson C, Gagnon DD. Correlates to the clinical diagnosis of premature ejaculation: results from a large observational study of men and their partners. J Urol. 2007;177(3):1059-64.

7. Frank E, Anderson C, Rubinstein D. Frequency of sexual dysfunction in "normal" couples. N Engl J Med. 1978;299(3):111-5.

8. Klusmann D. Sexual motivation and the duration of partnership. Arch Sex Behav. 2002;31(3):275-87.

9. Laumann EO, Nicolosi A, Glasser DB, Paik A, Gingell C, Moreira E, et al. Sexual problems among women and men aged $40-80 \mathrm{y}$ : prevalence and correlates identified in the Global Study of Sexual Attitudes and Behaviors. Int J Impot Res. 2005;17(1):39-57.

10. Rayssiguier Y, Guezennec CY, Durlach J. New experimental and clinical data on the relationship between magnesium and sport. Magnes Res. 1990;3(2):93-102.

11. Williams W. Secondary premature ejaculation. Aust N Z J Psychiatry. 1984;18(4):333-40.

12. Strassberg DS, Mahoney JM, Schaugaard M, Hale VE. The role of anxiety in premature ejaculation: a psychophysiological model. Arch Sex Behav. 1990;19(3):251-7.

13. Masters WH, Johnson VE. Human sexual inadequacy. Boston: Little, Brown \& Co; 1970.

14. Semans JH. Premature ejaculation: a new approach. South Med J. 1956;49(4):353-8.

15. Hawton K. Treatment of sexual dysfunctions by sex therapy and other approaches. Br J Psychiatry. 1995;167(3):307-14.

16. Barnes T, Eardley I. Premature ejaculation: the scope of the problem. J Sex Marital Ther. 2007;33(2):151-70.

17. McCabe MP. Evaluation of a cognitive behavior therapy program for people with sexual dysfunction. J Sex Marital Ther. 2001;27(3):259-71.

18. Althof SE. Psychological treatment strategies for rapid ejaculation: rationale, practical aspects, and outcome. World J Urol. 2005;23(2):89-92.

19. Morales A, Barada J, Wyllie MG. A review of the current status of topical treatments for premature ejaculation. BJU Int. 2007;100(3):493-501.

20. Busato W, Galindo CC. Topical anaesthetic use for treating premature ejaculation: a double-blind, randomized, placebo-controlled study. BJU Int. 2004;93(7):1018-21.

21. Choi HK, Jung GW, Moon KH, Xin ZC, Choi YD, Lee WH, et al. Clinical study of SS-cream in patients with lifelong premature ejaculation. Urology. 2000;55(2):257-61.

22. Montejo AL, Llorca G, Izquierdo JA, Rico-Villademoros F. Incidence of sexual dysfunction associated with antidepressant agents: a prospective multicenter study of 1022 outpatients. Spanish Working Group for the Study of PsychotropicRelated Sexual Dysfunction. J Clin Psychiatry. 2001;62 Suppl 3:10-21. 
23. Chen J, Keren-Paz G, Bar-Yosef Y, Matzkin H. The role of phosphodiesterase type 5 inhibitors in the management of premature ejaculation: a critical analysis of basic science and clinical data. Eur Urol. 2007;52(5):1331-9.

24. Mattos RM, Marmo Lucon A, Srougi M. Tadalafil and fluoxetine in premature ejaculation: prospective, randomized, double-blind, placebo-controlled study. Urol Int. 2008:80(2):162-5.

25. Porst H, Montorsi F, Rosen RC, Gaynor L, Grupe S, Alexander J. The Premature Ejaculation Prevalence and Attitudes (PEPA) survey: prevalence, comorbidities, and professional help-seeking. Eur Urol. 2007;51 (3):816-23.

26. Giuliano F, Bernabé J, Gengo P, Alexandre L, Clément P. Effect of acute dapoxetine administration on the pudendal motoneuron reflex in anesthetized rats: comparison with paroxetine. J Urol. 2007;177(1):386-9.

27. Gengo PJ, View M, Giuliano F, McKenna KE, Chester A, Lovenberg T, et al. Monoaminergic transporter binding and inhibition profile of dapoxetine, a medication for the treatment of premature ejaculation [abstract]. J Urol. 2005;173(4):239.

28. Hiemke C, Härtter S. Pharmacokinetics of selective serotonin reuptake inhibitors. Pharmacol Ther. 2000;85(1):11-28.
29. Modi NB, Dresser MJ, Simon M, Lin D, Desai D, Gupta S. Single- and multiple-dose pharmacokinetics of dapoxetine hydrochloride, a novel agent for the treatment of premature ejaculation. J Clin Pharmacol. 2006;46(3):301-9.

30. Pryor JL, Althof SE, Steidle C, Rosen RC, Hellstrom WJ, Shabsigh R, et al. Efficacy and tolerability of dapoxetine in treatment of premature ejaculation: an integrated analysis of two double-blind, randomised controlled trials. Lancet. 2006;368(9539):929-37.

31. Brock GB, Buvat J, Giuliano FA, Althof S, Shabsigh R, Tesfaye F, et al. Improvement in sexual satisfaction of female partners of men with premature ejaculation (PE) treated with dapoxetine (DPX) [abstract]. J Urol 2008;179(4):431-2.

32. Symonds T, Roblin D, Hart K, Althof $S$. How does premature ejaculation impact a man s life? J Sex Marital Ther. 2003;29(5):361-70.

33. Moreira ED Jr, Brock G, Glasser DB, Nicolosi A, Laumann EO, Paik A, et al. Help-seeking behaviour for sexual problems: the global study of sexual attitudes and behaviors. Int J Clin Pract. 2005;59(1):6-16. 